\title{
IMPROVING ELEMENTARY SCHOOL TEACHERS' SKILLS IN USING THINK TALK WRITE LEARNING MODEL THROUGH ACADEMIC SUPERVISION
}

\author{
Asnawati $^{1}$, Ary Kiswanto Kenedi ${ }^{2}$ \\ ${ }^{1}$ SDN 23 Ujung Gurun, Padang, Indonesia \\ ${ }^{2}$ Universitas Samudra, Langsa, Indonesia \\ Iasnawatispd1963@gmail.com,2arykenedi@unsam.ac.id
}

\begin{abstract}
This research was motivated by the fact that most of the learning processes were not in accordance with the characteristics of elementary school students so that it had an impact on the quality of learning at schools that did not achieve the goal. The learning process included the process of planning, implementing, and assessing of the primary school teacher. The purpose of this study was to improve the teachers' skills in carrying out the learning process by using a cooperative model of Think Talk Write type. This research was a school action research that adapted Mc Taggart and Kemmist's classroom action research design. This research consisted of stages of planning, implementation, observation and reflection. This research activity was carried out at SDN 23 Ujung Gurun Padang involving 10 teachers. The data collection technique was an observation sheet measuring the results of the learning process which including planning skills, implementation abilities, and assessment abilities. The data analysis technique consisted of quantitative data. The research found that the teacher's average score in carrying out the learning process using the Think Talk Write type cooperative model in cycle 1 was 68.30 and got an average score of 85.46 in cycle 2. This proved that there was an increase in teachers' skills in carrying out the learning process by using a Think Talk Write type cooperative model through academic supervision activities. The implications of this research was that this model could be used as a reference for academic supervisors to improve the quality of learning for elementary school teachers.
\end{abstract}

Keywords: teacher skills, academic supervision, think talk write

\section{PENINGKATAN KETERAMPILAN GURU SEKOLAH DASAR DALAM MENGGUNAKAN MODEL PEMBELAJARAN THINK TALK WRITE MELALUI SUPERVISI AKADEMIK}

\begin{abstract}
ABSTRAK
Penelitian ini dilatarbelakangi oleh banyaknya proses pembelajaran yang tidak sesuai dengan karakteristik siswa sekolah dasar di sekolah yang peneliti pimpin sehingga berdampak kepada kualitas pembelajaran disekolah yang tidak mencapai tujuan. Proses pembelajaran tersebut meliputi proses perencanaan, pelaksanaan dan penilaian pembelajaran guru sekolah dasar. Tujuan penelitian ini adalah meningkatkan keterampilan guru dalam melaksanakan proses pembelajaran menggunakan model kooperatif tipe Think Talk Write. Penelitian ini merupakan penelitian Tindakan Sekolah yang menyadur desain penelitian Tindakan kelas Mc Taggart dan Kemmist. Penelitian ini terdiri dari tahap perencanaan, pelaksanaan, pengamatan dan refleksi. Kegiatan penelitian ini dilaksanakan di SDN 23 Ujung Gurun Kota Padang sebanyak 10 guru. Teknik pengumpulan data menggunakan lembar observasi pengukuran hasil proses pembeajaran yang meliputi kemampuan perencanaan, kemampuan pelaksanaan dan kemampuan penilaian. Teknik analisis data terdiri dari data kuantitatif. Temuan penelitian menemukan bahwa didapatkannya skor rata-rata guru dalam melaksanakan proses pembelajaran menggunakan model kooperatif tipe Think Talk Write pada siklus 1 sebesar 68,30 dan mendapatkan skor rata-rata pada siklus 2 sebesar 85,46 . Hal ini membuktikan bahwa terjadinya peningkatan keterampilan guru dalam melaksanakaan proses pembelajaran menggunakan mode kooperatif tipe Think Talk Write melalui kegiatan supervisi akademik. Implikasi penelitian ini dapat dijadikan referensi bagi supervisor akademik untuk meningkatkan kualitas pembelajaran guru sekolah dasar.
\end{abstract}

Kata Kunci: keterampilan guru, supervisi akademi, think talk write

\begin{tabular}{|c|c|c|}
\hline Submitted & Accepted & Published \\
\hline 12 Agustus 2021 & 08 September 2021 & 17 September 2021 \\
\hline
\end{tabular}

\begin{tabular}{|c|c|c|c|}
\hline Citation & $:$ & $\begin{array}{r}\text { Asnawati., \& Kenedi, A.K. (2021). Improving Elementary School Teachers’ Skills in Using Think Talk Write Learning } \\
\text { Model through Academic Supervision . Jurnal PAJAR (Pendidikan dan Pengajaran), 5(5), 1467-1474. DOI : } \\
\text { http://dx.doi.org/10.33578/pjr.v5i5.8507. }\end{array}$ \\
\hline
\end{tabular}

\section{PENDAHULUAN}

Proses Pendidikan merupakan sebuah proses yang bertujuan membelajarkan siswa agar dapat menjadi individu yang memiliki wawasan

cerdas dan berprilaku sesuai dengan nilai-nilai agama dan bangsa (Kenedi et al, 2019). Proses pendidikan bertanggung jawab untuk 
menghasilkan siswa yang mampu mengelola pengetahuan, kemampuan intelektual, dan kemampuan emosional dalam proses kehidupan sehari-hari (Kenedi et al, 2018). Untuk mencapai hal tersebut tidak terlepas dari tanggung jawab guru dalam proses pembelajaran disekolah. Dalam proses pembelajaran disekolah guru memiliki tanggung jawab untuk dapat melaksanakan proses pembelajaran dengan baik.

Guru merupakan subjek pembelajaran yang bertugas untuk dapat melaksanakan proses pembelajaran (Kiswanto, 2017). Ada tiga tugas utama guru dalam proses pembelajaran yaitu merancang proses pembelajaran, melaksanakan pembelajaran dan melakukan penilaian pembelajaran (Ariani and Kenedi, 2018). Perancangan pembelajaran merupakan aktivitas guru dalam mendesain proses pembelajaran yang akan dilaksanakan (Rienties at al, 2017). Kegiatan perancangan pembelajaran dapat berupa pembuatan silabus, perancangan rencana pelaksanaan pembelajaran (RPP), pengembangan lembar kerja siswa, pengembangan penilaian dan segala sesuatu yang akan digunakan pada proses pembelajaran. Pelaksanaan pembelajaran merupakan proses kegiatan pembelajaran yang telah disusun dan disesuaikan dengan model maupun metode pembelajaran yang dipilih untuk mencapai tujuan pembelajaran (Arnold, 2014). Sedangkan yang dimaksud dengan penilaian pembelajaran adalah proses untuk mengukur ketercapaian proses pembelajaran (Hendri and Kenedi, 2018). Ketiga kegiatan ini merupakan tugas wajib yang harus dilaksanakan oleh guru. Termasuk diantaranya guru disekolah dasar.

Sekolah dasar merupakan lembaga formal yang memiliki tanggung jawab besar terhadap proses penyerapan ilmu pengetahuan dan keterampilan dasar siswa (Helsa and Kenedi, 2018). Oleh sebab itu guru sekolah dasar harus mampu mendesaian dan melaksanakan pembelajaran yang mampu mencapai tujuan pembelajaran yang telah disepakati. Namun berdasarkan kajian literatur yang peneliti lakukan ditemukan bahwa banyak nya permasalahan yang dihadapi oleh guru sekolah dasar. Permasalahan yang dihadapi adalah tidak sesuainya proses pembelajaran yang dilaksanakan dengan karakteristik siswa sekolah dasar (Kenedi et al, 2018). Siswa sekolah dasar merupakan siswa yang berada pada masa operasional kongkret (Mansur et al, 2017; Kenedi et al 2019). Pada masa ini siswa harus dibelajarkan dari bendabenda nyata serta siswa belajar secara aktif dalam proses menemukan informasi (Kenedi et al, 2019). Sehingga diperlukan sebuah pembelajaran yang dapat mengaktifkan siswa.

Namun berdasarkan observasi yang peneliti lakukan di sekolah yang peneliti pimpin di SDN 23 Ujung Gurun Kota Padang ditemukan beberapa fakta bahwa RPP yang digunakan oleh guru merupakan RPP yang didownload dari internet. RPP tersebut setelah peneliti analisis tidak bersifat kontekstual dan tidak sesuai dengan karakteristik siswa sekolah dasar. Selain itu ketika guru melaksanakan proses pembelajaran ditemukan bahwa guru tidak melaksanakan RPP yang telah didownload tersebut. Guru hanya menggunakan metode ceramah dalam proses pembelajaran. Selain itu guru juga tidak mengaktifkan siswa dalam menemukan informasi pembelajaran. Hal ini mengakibatkan siswa menjadi pasif dan cendrung bosan terhadap proses pelaksanaan pembelajaran yang dilaksanakan oleh guru. Pada proses penilaian yang dilaksanakan guru terlihat banyaknya tugas dan ulangan harian yang belum dinilai oleh guru. Guru juga hanya berfokus kepada penilaian kognitif siswa saja. Dari hasil observasi tersebut terlihat bahwa guru di sekolah yang peneliti pimpin belum melaksanakan proses pembalajaran yang sesuai dengan karakteristik siswa sekolah dasar. Oleh sebab itu perlunya upaya memperbaiki permasalahan tersebut.

Salah satu upaya yang dapat dilakukan adalah dengan melaksanakan supervisi akademik. Supervisi akademik merupakan sebuah aktivitas yang bertujuan untuk meningkatkan kualitas pembelajaran melalui peningkatan proses dan hasil pembelajaran (Azwardi, 2020; Saihu, 2020). Kegiatan supervisi akademis dilakukan oleh kepala sekolah kepada guru dengan tujuan memperbaiki permasalahan yang dihadapi oleh guru (Asniarny, 2019).

Berdasarkan permasalahan di atas dinyatakan bahwa proses pembelajaran yang 
dilaksanakan oleh guru tidak sesuai dengan karakteristik pembelajaran disekolah dasar yang meliputi proses perencanaan, pelaksanaan dan penilaian pembelajaran. Maka diperlukanlah perbaikan proses pembelajaran. Berdasarkan kajian literatur yang peneliti lakukan ditemukan bahwa salah satu proses pembelajaran yang sesuai dengan karakteristik pembelajaran disekolah dasar adalah proses pembelajaran menggukan model kooperatif tipe Think Talk Write (Dery and Putra, 2019). Model kooperatif tipe Think Talk Write merupakan sebuah model pembelajaran yang bersifat kerjasama dengan memberikan kesempatan kepada siswa untuk dapat memahami permasalahan pembelajaran dan aktif secara berkolaboratif menemukan solusi permasalahan serta menuliskan solusi tersebut melalui tulisan dengan bahasa sendiri (Kusuma et al, 2020). Banyak penelitian yang menyatakan bahwa model kolaboratif tipe Think Talk Write ini dapat meningkatkan kualitas pembelajaran (Supandi et al, 2018; Bustami et al, 2019; Listiana and Bahri, 2019). Oleh sebab itu peneliti ingin meningkatkan kemampuan guru dalam proses pembelajaran dalam menggunakan model pembelajaran tipe Think Talk Write sebagai upaya mengatasi permasalahan pembelajaran yang dialami oleh guru.

Penelitian ini didukung oleh peneliti sebelumnya yang oleh Astuti (2017) yang menyatakan bahwa telah meningkatkan kemampuan guru dalam melaksanakan penilaian pembelajaran melalui supervisi akademik. Namun penelitian ini menjadi berbeda karena penelitian ini mengfokuskan peningkatkan proses pembelajaran yang meliputi proses perencanaan, pelaksanaan dan penilaian pembelajaran pada guru sekolah dasar. Oleh sebab itu tujuan penelitian ini adalah untuk meningkatkan kemampuan guru dalam melaksanakan proses pembelajaran model kolaboratif tipe Think Talk Write melalui kegiatan supervisi akademik,

Penelitian ini penting dilaksanakan mengingat bahwa proses pembelajaran yang dilaksanakan oleh guru akan mempengaruhi kualitas pembelajaran siswa. Selain itu proses penelitian ini juga merupakan bagian dari pengembangan keprofesionalan guru sekolah dasar dalam meningkatkan kualitas pembelajaran

\section{METODE PENELITIAN}

Penelitian ini merupakan penelitian tindakan sekolah dengan menyadur proses pelaksanaan penelitian tindakan kelas Mc Taggart dan Kemmist. Penelitian ini terdiri dari tahap perencanaan, pelaksanaan, pengamatan dan refleksi. Pada tahapan perencanaan peneliti menyusun jadwal, penyusun rencana kegiatan dan penyusun instrument penilaian. Pada tahapan pelaksanaan peneliti melakukan kegiatan inti supervisi akademik. Pada tahapan pengamatan dilakukan proses penilaian kepada guru dan pada tahapan refleksi dilakukan proses analisis untuk memperbaiki kesalahan yang terjadi.

Kegiatan penelitian ini dilaksanakan di SDN 23 Ujung Gurun Kota Padang sebanyak 10 guru pada semester ganjil tahun 2020. Teknik pengumpulan data menggunakan lembar observasi pengukuran hasil proses pembelajaran yang meliputi kemampuan perencanaan, kemampuan pelaksanaan dan kemampuan penilaian. Teknik analisis data terdiri dari data kuantitatif. Data kuantitatif untuk menganalis hasil lembar observasi:

1. Menghitung nilai rata-rata pelaksanaan pembelajaran

Adapun rumus yang digunakan yaitu

$$
P=\frac{\text { Skor yang didapat }}{\text { Skor maksimal }} \times 100
$$

2. Menghitung ketuntasan klasikal

$$
X=\frac{\text { Jumlah guru yang mendapatkan nilai } \geq 75}{\text { Jumlah semua guru }} \times 100
$$

Perhitungan persentase dikelompokan menjadi dua bagian yaitu siswa yang mendapat nilai samat dan diatas 75 dikategorikan tuntas sedangkan nilai yang mendapatkan nilai dibawh 75 dikategorikan tidak tuntas. Adapun indikator keberhasilan PTS ini adalah keterampilan guru dalam melasksanakan proses pembelajaran mendapakan skor minimal 75 dengan ketuntasan belajar klasikal $75 \%$. 


\section{HASIL DAN PEMBAHASAN}

Tahapan pertama penelitian ini adalah tahapaan perancangan. Pada tahapan perancangan ini peneliti dan guru secara bersama merancang kegiatan perbaikan yang akan dilaksanakan. Tahapan perancangan ini terdiri dari penyusunan jadwal, penyusunan rencana kegiatan dan penyusunan instrument penilaian. Pada tahapan perencanaan peneliti juga melakukan analisis terhadap temuan pada saat observasi dan menyusun rencana perbaikan yang tepat untuk mengatasi permasalahan tersebut.

Tahapan selanjutnya adalah tahapan pelaksanaan kegiatan perbaikan. Pada tahapan pelaksanaan kegiatan ini guru dibina untuk melaksanakan proses pembelajaran menggunakan model kooperatif tipe Think Talk Write. Guru dilatih untuk merancang RPP dengan menggunakan model kooperatif tipe Think Talk Write. Guru dilatih untuk mengisi identitas sekolah, merumuskan tujuan pembelajaran berdasarkan kompetensi dasar dan indicator tujuan pembelajaran, mengembangkan materi pembelajaran, memilih media pembelajaran yang sesuai, mengembangkan sumber belajar, mengembangkan langkah-langkah pembelajaran berdasarkan langkah pembelajaran model kooperatif tipe Think Talk Write, dan pengembangan penilaian hasil belajar. Guru juga dilatih untuk mengembangkan penilaian berdasarkan model kooperatif tipe Think Talk Write yang meliputi penilaian aspek pengetahuan, keterampilan dan sikap. Kemudian RPP dan penilaian yang dikembangkan oleh guru diberikan penilaian.

Setelah guru dilatih untuk merancang RPP, maka selanjutnya guru dilatih untuk melaksanakan proses pembelajaran dengan menggunakan model kooperatif tipe Think Talk Write. Pada kegiatan ini guru juga diminta untuk melaksanakan proses pembelajaran berdasarka RPP dan penilaian yang telah dikembangkan di kelas masing-masing.

Pada tahapan pengamatan. Pada saat guru mengembangkan RPP dan penilaian juga dilakukan penilaian terhadap RPP dan penilaian hasil belajar tersebut. Selain itu proses pelaksanaan pembelajaran model kooperatif tipe Think Talk Write yang dilaksanakan oleh guru dikelas masingmasing juga diberikan penilaian. Adapun rekapitulasi penilaian RPP, proses pembelajaran dan penilaian hasil belajar sebagai berikut:

Tabel 1. Rekapitulasi Penilaian Siklus 1

\begin{tabular}{ll}
\hline \multicolumn{1}{c}{ Aspek } & Skor Rata-Rata \\
\hline Perancangan RPP & 65.92 \\
Perancangan penilaian & 66.78 \\
Pelaksanaan Pembalajaran & 72.34 \\
Pelaksanaan penilaian & 68.19 \\
Rata-rata & 68.30 \\
\hline
\end{tabular}

Dari tabel 1 tersebut terlihat bahwa hasil rata-rata keterampilan guru dalam melaksanakan proses pembelajaran menggunakan model kooperatif tipe Think Talk Write mendapatkan skor akhir yaitu 68,30 . Setelah dilakukan pengamatan tersebut maka dilakukan analisi pada tahapan refleksi.

Tahapan refleksi adalah tahapan untuk menganalisis kegiatan perbaikan yang telah dilakukan. Berdasarkan hasil pengamatan terlihat bahwa guru mendapatkan skor rata 68,30. Hal ini membukti bahwa guru masih belum mencapai indicator keberhasilan yang telah ditetapkan.
Adapun ketercapaian ini juga dikarenakan adanya beberapa kegiatan yang belum optimal dilakukan pada proses pelaksanaan kegiatan diantaranya pada proses perancangan RPP guru masih belum maksimal pada proses pengembangan kegiatan pembelajaran, pada saat pelaksanaan pembelajaran guru masih kaku dengan model kooperatif tipe Think Talk Write yang digunakan, selain itu pada proses penilaian guru masih berfokus kepada penilaian pengetahuan saja. Oleh sebab itu maka perlu perbaikan kegiatan pembelajaran yang dilaksanakan pada siklus kedua. 
Pada siklus kedua, tahapan perencanaan yang dilakukan sama dengan kegiatan pada siklus 1 yaitu penyusunan jadwal, penyusunan rencana kegiatan dan penyusunan instrument penilaian. Tahapan selanjutnya yaitu tahapan pelaksanaan, peneliti kembali melatih guru dalam merancang RPP dan penilaian hasil belajar dengan menggunakan model kooperatif tipe Think Talk Write. Pada kegiatan ini peneliti benar-benar membimbing guru untuk mengembangkan RPP dan penilaian hasil belajar dengan menggunakan model kooperatif tipe Think Talk Write. Pada kegiatan selanjutnya guru melaksanakan proses pembelajaran dikelas. Pada kegiatan ini terlihat guru semangat yang berdampak kepada antusias siswa dalam melaksanakan proses pembelajaran.

Pada tahapan pengamatan dilakukan penilaian RPP, penilaian hasil belajar dan proses pelaksanaan pembelajaran yang dilakukan. Adapun rekapitulasi penilaian RPP, proses pembelajaran dan penilaian hasil belajar sebagai berikut:

Tabel 2. Rekapitulasi Penilaian Siklus 2

\begin{tabular}{lc}
\hline Aspek & Skor Rata-Rata \\
\hline Perancangan RPP & 87.12 \\
Perancangan penilaian & 84.67 \\
Pelaksanaan pembalajaran & 83.19 \\
Pelaksanaan penilaian & 86.87 \\
Rata-rata & 85.46 \\
\hline
\end{tabular}

Dari tabel 2 tersebut terlihat bahwa hasil rata-rata keterampilan guru dalam melaksanakan proses pembelajaran menggunakan model kooperatif tipe Think Talk Write mendapatkan skor akhir yaitu 85,46. Setelah dilakukan pengamatan tersebut maka dilakukan analisis pada tahapan refleksi.

Berdasarkan hasil pengamatan tersebut terlihat bahwa skor yang didapatkan telah mencapai indicator keberhasilan yang telah ditetapkan. Maka berdasarkan kesepakatan peneliti dengan guru pada tahapan refleksi ini adalah penelitian dicukupkan sampai siklus kedua ini. Dari hasil peneitian ini terlihat peningkatkan keterampilan guru dalam melaksanakan proses pembelajaran dengan model kooperatif tipe Think Talk Write. Adapun visualiasi peningkatan tersebut dapat terlihat pada gambar berikut:

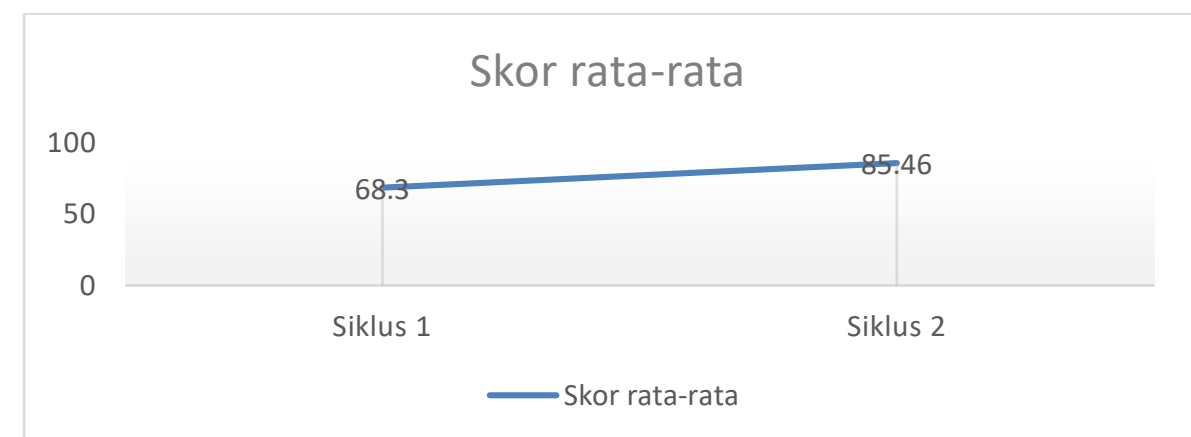

Gambar 1. Peningkatan Keterampilan Guru dalam Proses Pembelajaran

Dari Gambar 1 tersebut terlihat bahwa terjadinya peningkatkan keterampilan guru dalam melaksanakan proses pembelajaran menggunakan model kooperatif tipe Think Talk Write melalui kegiatan supervisi akademik. Penelitian ini didukung oleh penelitian yang dilakukan oleh
Rosilawati (2020) yang menyatakan terjadinya peningkatan keterampilan guru dalam Menyusun perangkat pembelajaran melalui supervisi akademik. Penelitian ini memiliki kesamaan yaitu sama-sama menggunakan supervisi akademik dalam meningkatkan keterampilan guru. Namun 
menjadi temuan yang berbeda karena penelitian ini difokuskan kepada peningkatan guru dalam melaksanakan proses pembelajaran menggunakan model kooperatif tipe Think Talk Write yang meliputi perencanaan, pelaksanaan dan penilaian pembelajaran. Sehingga temuan ini membuktikan bahwa melalui supervisi akademik dapat meningkatkan keterampilan guru dalam melaksanakan pembelajaran menggunakan model kooperatif tipe Think Talk Write.

Supervisi akademik merupakan kegiatan yang dilakukan oleh pimpinan (kepala sekolah) dalam mengembangkan segala potensi guru agar dapat terlaksananya tujuan pendidikan secara efektif dan efisien (Purbasari, 2015). Supervisi akademik bertujuan untuk membantu guru dalam meningkatkan dan mengembangkan kompetensi dan keprofesionalan dalam proses pembelajaran (Suhayati, 2013). Pada kegiatan ini supervisi akademik dapat meningkatkan keterampilan guru dalam proses pembelajaran (Sitaasih, 2020). Hal ini dikarenakan pada kegiatan supervisi akademik difokuskan kepada permasalahan yang dihadapi oleh guru. Pada kegiatan supervisi akademik dilakukan dengan memberikan bimbingan secara actual sehingga permasalahan yang dihadapi oleh guru dapat teratasi (Sumarni, 2019). Selain itu pada supervisi akademik guru diberikan kesempatan untuk dapat memperbaiki kelemahan yang dilakukan sehingga terlihatlah proses peningkatan guru (Hazrullah and Furqon, 2015). Hal-hal ini lah yang menjadikan faktor terjadinya peningkatkan kemampuan keterampilan guru.

Hasil peneitian ini selain bermanfaat bagi guru. Hal ini juga akan berdampak kepada siswa. Dengan meningkatkan keterampilan guru dalam melaksanakan proses pembelajaran maka akan meningkatkan kualitas siswa dalam mencapai tujuan pembelajaran. Selain itu hasil penelitian ini juga dapat dijadikan referensi bagi kepala sekolah dalam melaksanakan supervisi akademik

\section{SIMPULAN DAN REKOMENDASI}

Hasil penelitian ini menemukan bahwa didapatkannya skor rata-rata guru dalam melaksanakan proses pembelajaran menggunakan model kooperatif tipe Think Talk Write pada siklus 1 sebesar 68,30 dan mendapatkan skor rata-rata pada siklus 2 sebesar 85,46. Hal ini membuktikan bahwa terjadinya peningkatan keterampilan guru dalam melaksanakaan proses pembelajaran menggunakan model kooperatif tipe Think Talk Write melalui kegiatan supervisi akademik. Penelitian ini merekomendasikan bahwa perlu nya kegiatan supervisi akademik secara berkala agar meningkatnya keterampilan guru dalam proses pembelajaran.

\section{DAFTAR PUSTAKA}

Ariani, Y., \& Kenedi, A. K. (2018). Model Polya dalam peningkatan hasil belajar matematika pada pembelajaran soal cerita volume di sekolah dasar. Jurnal Inspirasi Pendidikan, 8(2), 25-36.

Arnold-Garza, S. (2014). The flipped classroom teaching model and its use for information literacy instruction. Communications in information literacy, 8(1), 9-14.

Asniarny, A. (2019). Pelaksanaan Supervisi Akademik Pengawas Sekolah Dalam Meningkatkan Kinerja Guru Sekolah Dasar Di Kota Dumai. Jurnal Pajar (Pendidikan dan Pengajaran), 3(4), 764772.

Astuti, S. (2017). Supervisi akademik untuk meningkatkan kompetensi guru di SD Laboratorium UKSW. Scholaria: Jurnal Pendidikan Dan Kebudayaan, 7(1), 4959.

Azwardi, A. (2020). Efforts to improve teacher competency in developing learning materials through collaborative academic supervision. Indonesian Educational Administration and Leadership Journal, 2(1), 1-12.

Bustami, Y., Riyati, Y., \& Julung, H. (2019). Think Talk Write with pictured cards on human digestive system: impact of critical thinking skills. Biosfer: Jurnal Pendidikan Biologi, 12(1), 13-23.

Dery, D. W., \& Putra, K. E. (2019). Penerapan model kooperatif tipe Think Talk Write untuk meningkatkan keterampilan menulis karangan narasi pada siswa sekolah dasar. Jurnal Pendidikan dan 
Konseling (JPDK), 1(1), 25-37.

Hazrullah, H., \& Furqan, F. (2018). Kompetensi

Profesional Guru Bimbingan Konseling

Dalam Pemecahan Masalah Belajar

Siswa Di Man Rukoh Banda

Aceh. Jurnal Ilmiah Didaktika: Media

Ilmiah Pendidikan dan

Pengajaran, 18(2), 245-258.

Helsa, Y., \& Kenedi, A. K. (2019). Edmodo-Based Blended Learning Media in Learning Mathematics. Journal Of Teaching And Learning In Elementary Education (JTLEE), 2(2), 107-117.

Hendri, S., \& Kenedi, A. K. (2018). Pengembangan perangkat pembelajaran matematika berbasis discovery learning untuk meningkatkan kemampuan pemecahan masalah siswa kelas VIII SMP. Jurnal Inspirasi Pendidikan, 8(2), 10-24.

Kenedi, A. K., Chandra, R., \& Fitria, Y. (2019, December). Problem based learning: a way to improve critical thinking ability of elementary school students on science learning. In Journal of Physics: Conference Series (Vol. 1424, No. 1, p. 012037). IOP Publishing.

Kenedi, A. K., Helsa, Y., \& Hendri, S. (2018). Pengembangan Bahan Ajar Matematika Berbasis Alquran Di Sekolah Dasar. Jurnal Inovasi Pendidikan Dan Pembelajaran Sekolah Dasar, 2(1),1-10.

Kenedi, A. K., Helsa, Y., Ariani, Y., Zainil, M., \& Hendri, S. (2019). Mathematical Connection of Elementary School Students to Solve Mathematical Problems. Journal on Mathematics Education, 10(1), 69-80.

Kenedi, A. K., Hendri, S., \& Ladiva, H. B. (2018). Kemampuan Koneksi Matematis Siswa Sekolah Dasar Dalam Memecahkan Masalah Matematika. Numeracy, 5(2), 226-235.

Kiswanto, A. (2017, September). The effect of learning methods and the ability of students think logically to the learning outcomes on natural sciences of grade ivs student. In 9th International Conference for Science Educators and Teachers (ICSET 2017) (pp. 1040-1046). Atlantis Press.

Kusuma, A. P., Rahmawati, N. K., Putra, F. G., \& Widyawati, S. (2020, February). The Implementation of Think Pair Share (TPS), Think Talk Write (TTW), and Problem Based Instruction (PBI) Learning Model on StudentS'Mathematics Learning Outcomes. In Journal of Physics: Conference Series (Vol. 1467, No. 1, p. 012065). IOP Publishing.

Listiana, L., \& Bahri, A. (2019). Empowering Student's Creative Thinking Skill in Biology Classroom: Potential of Group Investigation Combined with Think Talk Write (GITTW) Strategy. Humanities \& Social Sciences Reviews, 7(3), 477-483.

Mansur, M., Helsa, Y., \& Kenedi, A. K. (2017). AlQuran Based Learning Strategy in Teaching Mathematics at Primary Education. Advances in Social Science, Education and Humanities Research, 169, 304-306.

Purbasari, M. (2015). Pengaruh supervisi akademik terhadap kinerja mengajar guru di sekolah dasar. Journal of elementary education, 4(1), 46-52.

Rienties, B., Nguyen, Q., Holmes, W., \& Reedy, K. (2017). A review of ten years of implementation and research in aligning learning design with learning analytics at the Open University UK. Interaction Design and Architecture (s), 33, 134154.

Rosilawati, T. (2020). Supervisi Akademik dalam Upaya Peningkatan Motivasi Guru Menyusun Perangkat Persiapan Pembelajaran. Jurnal Penelitian Tindakan Sekolah dan Kepengawasan, 2(2).

Saihu, S. (2020). The Urgency Of Total Quality Management In Academic Supervision To Improve The Competency of Teachers. Edukasi Islami: Jurnal Pendidikan Islam, 9(02), 297-323.

Sitaasih, D. K. (2020). Supervisi Akademik untuk 
Meningkatkan Kompetensi Guru Dalam Proses Pembelajaran di SD. Jurnal Ilmiah Sekolah Dasar, 4(2), 241-247.

Suhayati, I. Y. (2013). Supervisi Akademik Kepala Sekolah, Budaya Sekolah Dan Kinerja Mengajar Guru. Jurnal Administrasi Pendidikan, 17(1),1-10

Sumarni, S. (2019). Peningkatan Kinerja Guru dalam Manajemen Pengelolaan Kelas melalui Supervisi Klinis di SDN 6 Lenek Daya Kecamatan Aikmel. EDISI, 1(2), 266-286.

Supandi, S., Waluya, S. B., Rochmad, R., Suyitno, H., \& Dewi, K. (2018). Think-TalkWrite Model for Improving Students' Abilities in Mathematical Representation. International Journal of Instruction, 11(3), 77-90. 